\title{
Participatory and Collaborative Governance for Sustainable Flood Risk Management: An emerging research agenda
}

\author{
Edward Challies, Jens Newig, Thomas Thaler, Elisa Kochskämper, Meike Levin-Keitel
}

Floods have, over the last half-century, caused severe damage to infrastructure and property, impacted negatively on economic activity, and brought about widespread loss of life and human suffering (Barredo 2009; Jongman et al. 2012; UNISDR 2011). The multiple causes and consequences of flooding result from human-environment interaction in complex social-ecological systems. Floods, while fundamentally natural phenomena, are exacerbated by environmental impacts of human activity (e.g. modification of waterways, deforestation of catchments, development on floodplains). Similarly, measures to reduce flood risk (including engineered flood protection infrastructure and non-structural measures such as land use planning and flood proofing) have important environmental impacts. Furthermore, land use change or structural defence measures in one place may affect flood risk in upor down-stream communities in ways that are difficult to predict in advance or even to demonstrate following a flood event (Thaler et al. 2015). The complex interaction of social, ecological and physical processes in flooding poses significant challenges for understanding, modelling and managing floods (Wheater 2002). Therefore both the drivers of increased flood risk and the implications of flooding touch on a wide range of sectors, and efforts to plan for and manage floods confront considerable complexity and uncertainty (Hall \& Solomatine 2008), and must balance and mediate among multiple sectors and competing interests.

Recognition of these factors, coupled with recurring flood disasters despite ever improving structural defences, has seen a shift in the management of floods over the last two decades towards an integrative risk management paradigm (Hall et al. 2003; Heintz et al. 2012; Johnson \& Priest 2008; PenningRowsell et al. 2006). This emergent paradigm recognises the limitations of an over-reliance on topdown expert-led planning, structural flood defences, and 'hard' engineering solutions. Rather than pursuing total flood protection and security, there is a shift in emphasis towards accommodating a certain (socially acceptable) level of risk ${ }^{1}$. However, it is also recognised that fragmented approaches to risk management are suboptimal, and integrated management is increasingly called for (WMO 2006a; 2006b; Merz et al. 2010). Integrated flood risk management (FRM) entails complementing structural defence measures with non-structural, or 'soft' measures for reducing the effects of flooding (e.g. spatial planning, awareness raising, insurance), and aligning FRM with wider environmental and natural resource management planning in river basins ${ }^{2}$. Alongside the principles of risk-based decision making and integrative management, stakeholder engagement and public participation are seen as central to effective FRM, and appear prominently in most related policy statements and management frameworks (Huitema et al. 2009).

\footnotetext{
${ }^{1}$ The notion of risk central to FRM is usually defined in terms of the expected losses from flooding over a specified area and time period. Flood risk, in this sense, comprises the magnitude of the flood hazard in terms of frequency and severity, the exposure of human activities to flooding, and the vulnerability of the elements exposed (WMO 2006b; Schanze 2006).

${ }^{2}$ In this regard, integrated FRM draws heavily on integrated water resources management (IWRM), with its roots in the Dublin Principles on water and sustainable development (Newig \& Challies 2014) - and is therefore likely prone to similar conceptual limitations and practical challenges to IWRM (see e.g. Medema et al. 2008).
} 
This integrated and participatory risk-based management approach is becoming institutionalised at different levels (e.g. IRGC 2012; Renn 2008; UNECE 2000; WMO 2009). It has been embodied in Europe in numerous national-level reforms over the past decade and, most notably, in the $2007 \mathrm{EU}$ Floods Directive ${ }^{3}$, which mandates flood risk management planning for all member states, and explicitly requires that the public be fully informed, and that interested parties have the opportunity to be actively involved, at all stages in the FRM planning process (Newig et al. 2014). The basic rationale for stakeholder and public participation in flood risk management planning is reflected in shifts in environmental governance more generally over the last half century, wherein participatory decision-making is assumed to lead to better decisions and plans, improved implementation and compliance, more beneficial social outcomes, greater legitimacy of planning processes and, ultimately, better environmental impacts as compared to top-down, administrative decision-making (e.g. Beierle \& Cayford 2002; Newig \& Fritsch 2009; Newig \& Kvarda 2012; Reed 2008).

Given that flood risk management is to be pursued on numerous fronts -addressing the magnitude of flood hazards, reducing the exposure of people and assets to flooding, and/or fostering the resilience of flood-prone communities - via a combination of structural and non-structural measures in an integrated fashion that takes account of wider environmental and resource management in river basins, there is certainly much scope for public participation in decision-making. In outlining reasons for public involvement in FRM, the World Meteorological Organisation (WMO 2006b: 32), for example, contends that participation can: identify common societal objectives and goals by bringing together diverse stakeholders to exchange information, ideas and knowledge; foster improved understanding and awareness through provision of information; enhance understanding between stakeholder groups, reducing conflict and promoting cooperation; identify different concerns and values and thereby foster consensus; ensure that the priorities of affected parties are addressed; build community resilience through cooperation and coordination; ensure the 'sustainability' of measures adopted; and promote autonomy and flexibility in decision-making and implementation. However, despite the potential of participatory approaches to achieve such goals, what determines whether or not this in fact occurs? What are the opportunities and challenges of participatory and collaborative approaches in FRM? What about FRM might distinguish it from public environmental decision-making more generally, so as to pose unique opportunities and challenges for participatory and collaborative governance?

While a large amount of research tackles analogous questions in neighbouring fields within environmental policy and governance (e.g. notably in water governance), there has been little research explicitly examining the role and implications of participatory decision-making in flood risk management (but for a very early exception see Fordham et al. 1991, and more recently Buchecker et al. 2013; Daniell et al. 2010; Fleischhauer et al. 2012; Hedelin \& Hjerpe 2015; Newig et al. 2014; Pahl-Wostl 2006; Rouillard et al. 2014; Sinclair et al. 2003; Tseng \& Pening-Rowsell 2012). Many contributions have examined adaptive and integrative management prescriptions, which advocate stakeholder engagement and participation to varying degrees (e.g. Becker et al. 2015; Huitema et al. 2009; Penning-Rowsell \& Johnson 2015; Medema et al. 2015; van Stokkom \& Witter 2008; Walker et al. 2014), but there is, we argue, a need for a greater degree of critical analysis of how and under what conditions participatory and collaborative approaches work (or not) in FRM.

Empirical evidence from neighbouring environmental policy fields supports competing claims as to the effectiveness of participation, and there is no reason to believe that the field of FRM should be any less fraught. Indeed FRM, insofar as it is concerned with planning in a natural hazards context, arguably has distinct implications for participatory decision-making. Stakeholder affectedness is arguably more direct than in many other environmental policy fields, as floods pose a direct threat to

\footnotetext{
${ }^{3}$ Directive 2007/60/EC of the European Parliament and of the Council of 23 October 2007, on the assessment and management of flood risks, entered into force on 26 November 2007.
} 
property, economic activity, and human life. As the risk-based management paradigm entails the social accommodation of flood risk at the community level, and a redistribution of responsibilities away from centralised authorities (Butler \& Pidgeon 2011; Johnson \& Priest 2008; Thaler \& Priest 2014), it implies a need for concerted engagement with and participation by different stakeholders both to raise awareness and capacity to confront flood hazards, and to arrive at locally accepted FRM interventions. As appropriate and acceptable levels of flood risk must be negotiated and determined at more localised scales, it would seem to make sense that rather localised participatory planning processes can best incorporate lay-local knowledge, represent community interests, provide relevant information, and develop plans that fit local context and community priorities. Some observers (e.g. Ingram 2013; Meinzen-Dick 2007) have held that there are no universal planning remedies, and institutional design and decision-making must take more account of context. Participatory and collaborative governance may offer a means to do just this, but as others have cautioned, such governance arrangements should also not be seen as a panacea (Bulkeley \& Mol 2003; Huitema et al. 2010; van der Heijden 2013), and much remains to be learned from careful analysis of how participatory FRM plays out in practice.

This special issue brings together a variety of papers from scholars working across several disciplines on different aspects of participatory FRM in the European context. In doing so, it responds to recent calls for more social scientific research on the role of participation in FRM (e.g. Mostert \& Jurnier 2009; Newig et al. 2014), and seeks to begin to address the research challenges discussed above. The eleven papers collected here are mostly drawn from two conference sessions convened by the guest editors in 2014: at the International Association for Society and Natural Resources $20^{\text {th }}$ International Symposium on Society and Resource Management (ISSRM) in Hannover, Germany; and at the Royal Geographical Society and Institute of British Geographers (RGS/IBG) Annual Conference in London, UK. The papers make conceptual and empirical contributions, drawing on cases from Germany, Switzerland, Austria and England, but with relevance for the wider European context and beyond.

Fundamental implications for public and stakeholder participation arise from how the costs and benefits of FRM are distributed, and this is examined by Geaves and Penning-Rowsell (2015), who consider whether FRM should be seen as delivering primarily public or private goods. As these authors note, this has important consequences for who should be involved in FRM planning processes, and the form that stakeholder engagement should take. While it is acknowledged that in general FRM can be considered as providing a public good, the authors usefully differentiate within this category, discussing FRM measures that might better be classified as delivering club goods, or priority public goods. They argue that given how unevenly the costs and benefits of FRM are borne in reality, it is often problematic to speak of (purely) public goods. They describe a tendency to increasingly localised FRM interventions, and see in this growing importance of spatially bounded public goods or club goods. Reflecting on the rise of 'partnership funding' in the UK, they suggest that many FRM schemes that would previously have been considered as providing 'pure' public goods, now appear to be providing a kind of club good, made excludable by the geographic scale of both the intervention itself and the distribution of responsibility for funding, implementation and maintenance. The partnership funding model itself does however open up a more definite role for public and stakeholder participation, as authorities must have communities and affected parties on-board. Overall, the authors suggest, this kind of rescaling of the provision of public goods in FRM - towards more local-level, community-based schemes - likely can facilitate more meaningful and effective stakeholder engagement, but it may also alter the public good nature of many FRM interventions, dragging them towards a type of club good, with elements of rivalry and excludability.

Taking up the theme of local stakeholder engagement by national-level competent authorities, Thaler and Levin-Keitel (2015) examine multi-level FRM in three case studies from England. They discuss 
how efforts to engage stakeholders and the public often give rise to a variety difficulties and conflicts, and tend to produce far more modest outcomes than intended. This is in part attributed to the fact that not all communities have equal capacity to advocate for their interests and priorities - even in participatory settings. The authors find that in cases where there is some pre-existing network of organised interests or groups, stakeholder engagement is likely to be more inclusive and more successful. In areas where this kind of social capital is absent, however, stakeholder engagement does not tend to reach down beyond the level of local authorities. Also reflecting on the partnership funding context, the authors see the increased obligation on the Environment Agency to consult with and engage stakeholders as being at least partially offset by the increased costs and demands paced upon communities that are not necessarily equipped to meet them. Furthermore, despite the notion of 'partnership', the balance of power in decision-making is argued to remain tipped clearly in favour of the authorities.

Turning to the nature of flood hazard, and particularly focusing on the occurrence of rare floods in urban regions, Hutter (2015) observes that rare floods can serve both to stimulate collaborative and participatory FRM, and to (re)centralise power and decision-making. The paper considers how collaborative governance might help deal with uncertainty and surprise in FRM, and distinguishes between collaborative planning efforts that seek to reduce uncertainty and avoid or minimise surprise, and collaborative approaches to learning from surprise to build resilience in the face of flood hazards. In the latter sense, uncertainty and surprise are seen as opportunities for 'sensemaking' through collaboration, which can aid post-flood recovery as well as build adaptive capacity. The paper discusses how a particular focus of collaborative efforts in FRM - on reducing risk or building resilience - implies particular assumptions about the role of uncertainty and surprise. The author argues that treating rare and damaging floods as 'unpredictable' disasters, too often justifies the exclusion of stakeholders from decision-making, or serves as an excuse for inaction. Rather, recognition of the predictability of damaging floods - or at least an ability to anticipate such events is a necessary first step to realising the potential of collaborative governance in FRM.

Public acceptance of integrated flood risk management is investigated by Buchecker, Ogasa and Maidl (2015), who analyse the relative acceptance of structural and non-structural measures in two case studies from Switzerland. While noting that the integrated adoption of structural and non-structural measures is both increasingly seen as best practice, and strongly encouraged by European law, they find that the 'shift' from flood protection to integrated FRM has been more complex on the ground and in the minds of residents, than in the policy discourse. Overall the surveyed public retained a preference for conventional, structural flood protection, and public 'buy-in' to integrated FRM was found to be very low in the sense that there were low levels of implementation of (and motivation to implement) individual- or household-level measures. But the authors do also find a degree of openness to non-structural measures, and the research identified among members of the public an appreciation for the connections between 'ecological' river basin management and FRM, indicating perhaps a latent acceptance of or openness to integrated FRM, and potential to align FRM planning with participatory river basin management planning and river revitalisation efforts already underway. As the authors explain, however, public attitudes toward FRM are not static, and following flood events public preference tends to swing strongly towards structural flood protection, which poses a challenge for integrated water resources management or river basin management. They call for more proactive and locally-tailored risk communication, in order to increase awareness of the benefits of measures at the individual and household levels, and synergies between FRM and river revitalisation.

Stakeholder participation in FRM planning, which might not receive much public attention at the time, frequently comes under intense scrutiny, and even attack, following flood disasters. Public perception of, and attitudes towards, FRM interventions are examined by Kuhlicke, Callsen and Begg (2015) through the lens of 'second order' reputational risks faced both by authorities with responsibility for 
FRM, and by other actors advocating for or taking part in participatory processes. Drawing on the case of the 2013 floods in the state of Saxony, the authors show how the post-flood public debate was characterised by attempts to undermine the credibility of both public participation processes and individual stakeholders involved. These debates, which played out primarily in the news media, saw prominent politicians deflecting blame and assigning responsibility onto participants in the FRM planning process, who were accused of delaying effective flood protection infrastructure, and thereby exacerbating flood damages. The effectiveness of participatory approaches, and even the right of stakeholders to participate, in FRM was thus widely challenged. Therefore, in the case studied, participation effectively reduced the legitimacy of the planning process (at least according to postflood public opinion), and was argued to have increased the vulnerability of communities - relative to the protection that would have been achieved under expert-led decision making and timely completion of structural flood defences. The paper argues that institutionalised practices of participation are closely linked with public and media discourses about participation - particularly in the field of FRM and in relation to flood disasters. Ultimately, these dynamics may serve to divert attention away from managing 'first-order' flood risks, and stifle participatory and collaborative approaches, as authorities are increasingly preoccupied with how they are perceived and the reputational risks that accompany this.

A core issue for participation in FRM is learning and knowledge exchange - both among participants, and between participants and competent authorities - and this is addressed from different perspectives by several papers. Benson, Lorenzoni and Cook (2015) consider the extent to which stakeholder engagement and participation fosters, and is enhanced by, social learning - both in terms of individual learning and 'community interaction learning'. The research draws evidence from Regional Flood and Coastal Committees in England, which were specifically set up to incorporate local (governmental and non-governmental) stakeholders and interests into regional scale FRM. The authors find that while individual-level instrumental learning did occur to varying degrees among Committee members, 'deeper' individual learning (i.e. fundamental change in understanding as opposed to simple knowledge acquisition) was not observed. This, it is suggested, may be attributed to the high levels of prior understanding among participants, and may occur more readily in processes where participants have different levels of understanding or hold a wider range of views. Community interaction learning through Committee deliberations was found to be highly variable. While trust, collective agreement and networking were high, the authors identify important constraints on group learning, which relate mainly to the top-down, rule-based institutional foundations of the processes. In particular, government priorities, which often did not match local priorities, remained highly influential in the Committee setting. The paper therefore raises important questions about who should learn in participatory FRM, how this may be enabled or constrained by institutional factors, and how social learning should contribute to effectiveness.

Individual and social learning in participatory FRM can be promoted via a variety of innovative tools and approaches. Evers, Jonoski, Almoradie and Lange (2015) discuss collaborative modelling (CM) as one such 'socio-technical' innovation, and consider how CM can foster different types of learning, which is deemed essential to fostering flood preparedness and building capacity for increased flood resilience. Drawing on the social learning literature, the paper describes how a collaborative modelling project designed and run by the authors in northern Germany, fostered learning among participants about the state of flood risk and FRM in the area, potential management options and their implications, stakeholders' interests and values in relation to FRM, and skills and capabilities for more effective collaborative approaches to FRM. The collaborative modelling process was explicitly designed to combine a range of socio-technical tools, including an online collaborative platform and interactive forum, and a collaborative modelling exercise with TOPSIS - a multi-criteria decision analysis technique - with 'traditional' participatory processes including workshops and stakeholder meetings. 
The authors find one of the most beneficial outcomes of their approach to be its capacity to foster learning among stakeholders about their own and others' interests, views and values relative to flood risk management - and to track how these may change over the course of a collaborative process as various management alternatives and scenarios are considered and negotiated. The paper argues that CM certainly holds potential for fostering learning, and calls for future research, incorporating formal evaluative methods, to analyse collaborative modelling in FRM over longer time periods and in different settings.

With the increased decision scope in an integrated FRM context, which encompasses a wider range of sectors and social, economic and environmental factors, there is a heightened need to integrate science and decision-making. Löschner, Nordbeck, Scherhaufer and Seher (2015) examine the integration of science and FRM decision-making in two 'scientist-stakeholder workshops' conducted in flood-prone municipalities in Austria. As they observe, while scientific and technological expertise (along with technical and engineering solutions) of course remains important in integrated FRM, increasingly it must be combined with different knowledge domains. In this sense, the part played by science in FRM has shifted somewhat, from its leading role in structural approaches to flood security, to one of decision support in more participatory planning for integrated FRM. The authors suggest that integrated scientific and stakeholder knowledge can contribute to more effective FRM measures, and argue that collaborative integrative assessment of flood risks via scientist-stakeholder workshops can deliver policy-relevant outcomes in this respect. This may result from the integration of complementary bodies of scientific and stakeholder knowledge, thereby improving the information available to decision-makers and raising awareness and understanding among stakeholders, or through stakeholder knowledge providing a kind of locally sensitised plausibility check on scientific knowledge. While the resource-intensive nature of the workshops is likely to limit wider adoption, the authors see some potential for this collaborative approach to be selectively employed for effective knowledge integration in collaborative FRM planning.

Given the diverse functions of participation in FRM, and the wide range of possibilities for organising and conducting participatory processes, a crucial issue is how agencies design such processes. What evidence is drawn upon, and how do they learn? Introducing the notion of 'governance learning' Newig, Kochskämper, Challies and Jager (2015) study learning by policy-makers about how to conduct effective participatory planning in FRM. The authors draw on the case of German FRM planning under the EU Floods Directive to explore 'governance learning' across the German federal states. In particular the paper discusses where policy-makers look for evidence, and how they learn about what might be effective procedures, in participatory FRM planning. The focus is therefore on the procedural dimensions of participatory FRM, rather than the substantive content of plans and measures or wider social outcomes of the planning process. The authors find that policymakers have so far tended to rely on prior experience in their own federal states (especially with water quality planning under the EU Water Framework Directive) to inform the design and carrying out of participatory FRM processes. Policymakers only sporadically look to experiences from other jurisdictions as a deliberate learning strategy. The authors advocate for more coordinated and systematic learning on designing effective governance.

Turning to the current European FRM context under the EU Floods Directive, Hartmann and Spit (2015) explore the emergence of the flood risk management plan as a new instrument in the paradigm shift from flood protection to risk management, and discuss the implications for legitimacy of flood governance. The authors discuss how the risk-based approach leads to differentiated levels of flood protection, which need to be negotiated locally with stakeholders. Two aspects of this shift have particularly significant implications for the legitimacy of FRM and, it is argued, demand attention to planning and decision-making processes. First, the spatial extension of integrated management to take in whole river basins (i.e. 'behind the dikes') requires balancing and bargaining between a wider range 
of land uses and spatial demands. This entails consideration and incorporation of the needs and priorities of more stakeholders, economic sectors and more policy fields in the planning process. Second, the provision of differentiated levels of flood protection given different flood scenarios (a requirement of the Floods Directive) also complicates spatial planning in river basins and necessitates further negotiation and decision-making as to acceptable levels of risk and protection. Whereas the prior flood security approach derived legitimacy primarily from the institutions responsible (input legitimacy) and the standard of flood protection delivered (output legitimacy), FRM is rather more reliant on throughput legitimacy in terms of public and stakeholder acceptance of and satisfaction with decision-making and planning processes. The authors contend that due to the nature of FRM, where core land uses and private property (values) are at stake, efforts to improve stakeholder collaboration and participation might usefully look to experiences in collaborative spatial planning, where land use and property values play a more central role than in many fields of environmental governance.

Focusing in yet greater detail on the implications of the EU Floods Directive, the contribution by Albrecht (2015) explores the legal framework for integrated FRM by detailing the legal requirements and scope for coordinating public participation in flood risk and river basin management planning. Focusing on the respective requirements of the 2007 Floods Directive and the 2000 Water Framework Directive, and looking in detail at their transposition in Germany, the paper provides a careful analysis of the extent to which the objectives of FRM and river basin management align and diverge. Noting that the Floods Directive explicitly requires coordination with Water Framework Directive planning, the paper maps out basic guiding criteria for coordinating participation in FRM and river basin management planning. In analysing how far these criteria are reflected in the German legislation, the paper finds that transposition into German law brought very little concretisation or harmonisation of participatory processes. While this is perhaps an opportunity missed, given the potential synergies and scope for avoiding conflicts that better alignment could bring, the author argues that the German legislation also need not impede coordination and integration of participatory planning. In fact, there remains considerable leeway that the individual federal states could take advantage of in designing integrated approaches but, the author observes, this has so far not occurred. It is argued, therefore, that a greater degree of stipulation of the procedural requirements around participation is required, as authorities' merely having the legal leeway to innovate in this regard has not so far led to coordination and integration.

Together the papers assembled here represent some of the latest work in the emerging field of research on participatory and collaborative governance in FRM. As several contributors suggest, there is potentially a lot to learn from experiences with and research on participation and collaboration in related policy fields, such as water governance and spatial planning, and this special issue can be seen as a step in that direction. But one clear message to emerge from the various findings reported in this collection is that FRM is also different in some important ways to neighbouring areas of environmental governance (particularly in relation to the more direct affectedness of stakeholders and the need for locally-negotiated solutions), and these differences raise important questions and pose particular challenges for the engagement of stakeholders and the public in decision-making and planning processes. Further research - some of which is foreshadowed here - should investigate precisely how, and under what conditions, participatory and collaborative governance contributes to effective and legitimate efforts to confront flood hazards, reduce exposure and vulnerability of communities, and thereby foster sustainable flood risk management. 


\section{References}

Albrecht, J. (2015). Legal framework and criteria for effectively coordinating public participation under the Floods Directive and Water Framework Directive: European requirements and German transposition. Environmental Science \& Policy. http://dx.doi.org/10.1016/j.envsci.2015.07.019

Barredo, J. I. (2009). Normalised flood losses in Europe: 1970-2006. Natural Hazards and Earth System Science, 9(1), 97-104.

Becker, G., Huitema, D. and Aerts, J. C. J. H. (2015). Prescriptions for adaptive comanagement: the case of flood management in the German Rhine basin. Ecology and Society 20(3): 1.

Beierle, T. C., \& Cayford, J. (2002). Democracy in Practice. Public Participation in Environmental Decisions. Washington DC: Resources for the Future.

Benson, D., Lorenzoni, I., \& Cook, H. (2015). Evaluating social learning in England flood risk management: An 'individual-community interaction' perspective. Environmental Science \& Policy. http://dx.doi.org/10.1016/j.envsci.2015.05.013

Buchecker, M., Menzel, S., Home, R. (2013). How much does participatory flood management contribute to stakeholders' social capacity building? Empirical findings based on a triangulation of three evaluation approaches. Natural Hazards and Earth System Sciences 13, 1427-1444.

Buchecker, M., Ogasa, D. M., \& Maidl, E. (2015). How well do the wider public accept integrated flood risk management? An empirical study in two Swiss Alpine valleys. Environmental Science \& Policy. http://dx.doi.org/10.1016/j.envsci.2015.07.021

Bulkeley, H., \& Mol, A. P. J. (2003). Participation and Environmental Governance: Consensus, Ambivalence and Debate. Environmental Values, 12(2), 143-154.

Butler, C., \& Pidgeon, N. (2011). From 'flood defence' to 'flood risk management': Exploring governance, responsibility, and blame. Environment and Planning C, 29(3), 533-547.

Daniell, K.A., White, I., Ferrand, N., Ribarova, I.S., Coad, P., Rougier, J.-E., Hare, M., Jones, N.A., Popova, A., Rollin, D., Perez, P., Burn, S. (2010). Co-engineering participatory water management processes: Theory and insights from Australian and Bulgarian interventions. Ecology and Society 15.

Evers, M., Jonoski, A., Almoradie, A., Lange, L. (2015). Collaborative decision making in sustainable flood risk management: a socio-technical approach and tools for participatory governance. Environmental Science \& Policy. doi

Fleischhauer, M., Greiving, S., Flex, F., Scheibel, M., Stickler, T., Sereinig, N., . . Firus, K. (2012). Improving the active involvement of stakeholders and the public in flood risk management tools of an involvement strategy and case study results from Austria, Germany and Italy. Natural Hazards and Earth System Sciences, 12(9), 2785-2798.

Fordham, M., Tunstall, S., \& Penning-Rowsell, E. C. (1991). Choice and preference in the Thames floodplain: the beginnings of a participatory approach? Landscape and Urban Planning, 20, 183-197.

Geaves, L. H., \& Penning-Rowsell, E. C. (2015). Flood Risk Management as a public or a private good, and the implications for stakeholder engagement. Environmental Science \& Policy. http://dx.doi.org/10.1016/j.envsci.2015.06.004

Hall, J., Meadowcroft, I., Sayers, P., and Bramley, M. (2003). Integrated Flood Risk Management in England and Wales. Natural Hazards Review, 4(3), 126-135.

Hall, J., Solomatine, D. (2008) A framework for uncertainty analysis in flood risk management decisions. International Journal of River Basin Management, 6(2), 85-98.

Hartmann, T., \& Spit, T.(2015). Legitimizing differentiated flood protection levels - Consequences of the European flood risk management plan. Environmental Science \& Policy. http://dx.doi.org/10.1016/j.envsci.2015.08.013

Hedelin, B., \& Hjerpe, M. (2015). Examining the benefits of collaboration: the Provider-User Matrix for collaborative flood risk management illustrated by the case of the Ljusnan River, Sweden. Journal of Natural Resources Policy Research, 7(1), 53-69. 
Heintz, M. D., Hagemeier-Klose, M., \& Klaus, W. (2012). Towards a Risk Governance Culture in Flood Policy: Findings from the Implementation of the 'Floods Directive' in Germany. Water, 4, 135-156.

Huitema, D., Cornelisse, C., Ottow, B. (2010). Is the Jury Still Out? Toward Greater Insight in Policy Learning in Participatory Decision Processes - the Case of Dutch Citizens' Juries on Water Management in the Rhine Basin. Ecology and Society 15.

Huitema, D., Mostert, E., Egas, W., Moellenkamp, S., Pahl-Wostl, C., \& Yalcin, R. (2009). Adaptive water governance: Assessing the institutional prescriptions of adaptive (co-)management from a governance perspective and defining a research agenda. Ecology and Society, 14(1), Article 26.

Hutter, G. (2015). Collaborative governance and rare floods in urban regions - Dealing with uncertainty and surprise. Environmental Science \& Policy. http://dx.doi.org/10.1016/j.envsci.2015.07.028

Ingram, H. (2013). No universal remedies: Design for contexts. Water International, 38(1), 6-11.

IRGC. (2012). An introduction to the IRGC Risk Governance Framework. International Risk Governance Council: Lausanne.

Johnson, C. L., \& Priest, S. J. (2008). Flood Risk Management in England: A Changing Landscape of Risk Responsibility? International Journal of Water Resources Development, 24(4), 513-525.

Jongman, B., Ward, P. J., \& Aerts, J. C. J. H. (2012). Global exposure to river and coastal flooding: Long term trends and changes. Global Environmental Change, 22(4), 823-835.

Kuhlicke, C., Callsen, I., \& Begg, C. (2015). Reputational risks and participation in flood risk management and the public debate about the 2013 flood in Germany. Environmental Science \& Policy. http://dx.doi.org/10.1016/j.envsci.2015.06.011

Löschner, L., Nordbeck, R., Scherhaufer, P., \& Seher, W. (2015). Scientist-stakeholder workshops: A collaborative approach for integrating science and decision-making in Austrian flood-prone municipalities. Environmental Science \& Policy. http://dx.doi.org/10.1016/j.envsci.2015.08.003

Medema, W., McIntosh, B. S., \& Jeffrey, P. J. (2008). From premise to practice: A critical assessment of integrated water resources management and adaptive management approaches in the water sector. Ecology and Society, 13(2).

Meinzen-Dick, R. (2007). Beyond panaceas in water institutions. PNAS, 104(39), 15200-15205.

Merz, B., Hall, J., Disse, M., Schumann, A. 2010. Fluvial flood risk management in a changing world. Natural Hazards and Earth System Sciences, 10, 509-527.

Mostert, E., \& Junier, S. J. (2009). The European flood risk directive: challenges for research. Hydrology and Earth System Sciences, 6, 4961-4988.

Newig, J., \& Challies, E. (2014). Water, rivers and wetlands. In P. G. Harris (Ed.), Routledge Handbook of Global Environmental Politics (pp. 439-452). London: Routledge.

Newig, J., Challies, E., Jager, N., \& Kochskämper, E. (2014). What Role for Public Participation in Implementing the EU Floods Directive? A comparison with the Water Framework Directive, early evidence from Germany, and a research agenda. Environmental Policy and Governance, $24,275-288$.

Newig, J., \& Fritsch, O. (2009). Environmental Governance: Participatory, Multi-Level - And Effective? Environmental Policy and Governance, 19(3), 197-214.

Newig, J., Kochskämper, E., Challies, E., \& Jager, N. W. (2015). Exploring governance learning: How policymakers draw on evidence, experience and intuition in designing participatory flood risk planning. Environmental Science \& Policy. http://dx.doi.org/10.1016/j.envsci.2015.07.020

Newig, J., \& Kvarda, E. (2012). Participation in environmental governance: legitimate and effective? In K. Hogl, E. Kvarda , R. Nordbeck \& M. Pregernig (Eds.), Environmental Governance. The Challenge of Legitimacy and Effectiveness (pp. 29-45). Cheltenham: Edward Elgar.

Pahl-Wostl, C., 2006. The Importance of Social Learning in Restoring the Multifunctionality of Rivers and Floodplains. Ecology and Society 11.

Penning-Rowsell, E. \& Johnson, C. (2015). The ebb and flow of power: British flood risk management and the politics of scale. Geoforum, 62, 131-142. 
Penning-Rowsell, E., Johnson, C., \& Tunstall, S. (2006). 'Signals' from pre-crisis discourse: Lessons from UK flooding for global environmental policy change? Global Environmental Change, 16(4), 323-339.

Reed, M. S. (2008). Stakeholder participation for environmental management: a literature review. Biological Conservation, 114(10), 2417-2431.

Renn, O. (2008). White Paper on Risk Governance: Toward an Integrative Framework. In O. Renn \& K. D. Walker (Eds.), Global Risk Governance: Concept and Practice Using the IRGC Framework (pp. 3-73). Netherlands: Springer.

Rouillard, J.J., Reeves, A.D., Heal, K.V., Ball, T., 2014. The role of public participation in encouraging changes in rural land use to reduce flood risk. Land Use Policy 38, 637-645.

Sinclair, A. J., Diduck, A., Morris-Oswald, T., \& Olczyk, M. (2003). Public involvement in flood management in the Red River basin: An assessment of a recent initiative. Canadian Water Resources Journal, 28(3), 461-480.

Schanze, J. (2006). Flood Risk Management - A Basic Framework. In J. Schanze, E. Zeman \& J. Marsalek (Eds.), Flood Risk Management: Hazards, Vulnerability and Mitigation Measures (pp. 1-20). Dordrecht: Springer.

Thaler, T., \& Levin-Keitel, M. (2015). Multi-level stakeholder engagement in flood risk management - A question of roles and power: Lessons from England. Environmental Science \& Policy. http://dx.doi.org/10.1016/j.envsci.2015.04.007

Thaler, T., \& Priest, S. (2014). Partnership funding in flood risk management: new localism debate and policy in England. Area, 46(4), 418-425.

Thaler, T., Priest, S., \& Fuchs, S. (2015). Evolving inter-regional co-operation in flood risk management: distances and types of partnership approaches in Austria. Regional Environmental Change, 1-13.

Tseng, C.-P., \& Penning-Rowsell, E. C. (2012). Micro-political and related barriers to stakeholder engagement in flood risk management. Geographical Journal, 178(3), 253-269.

UNECE. (2000). Guidelines on Sustainable Flood Prevention. United Nations Economic Commission for Europe: New York.

UNISDR (2011). Global Assessment Report on Disaster Risk Reduction 2011: Revealing Risk, Redefining Development. United Nations International Strategy for Disaster Risk Reduction. Geneva: United Nations.

van der Heijden, J. 2013. Is New Governance the Silver Bullet? Insights from the Australian Buildings Sector. Urban Policy and Research, 31(4), 453-471.

van Stokkom, H. T. C., \& Witter, J. V. (2008). Implementing integrated flood risk and land-use management strategies in developed deltaic regions, exemplified by The Netherlands. International Journal of River Basin Management, 6(4), 331-338.

Walker, G., Tweed, F., \& Whittle, R. (2014). A framework for profiling the characteristics of risk governance in natural hazard contexts. Natural Hazards and Earth System Sciences, 14(1), 155164.

Wheater, H.S., 2002. Progress in and prospects for fluvial flood modelling. Philosophical Transactions of the Royal Society A, 360, 1409-1431.

WMO (2006a). Environmental Aspects of Integrated Flood Management. Flood Management Policy Series. Geneva: World Meteorological Organization.

WMO (2006b). Social Aspects and Stakeholder Involvement in Integrated Flood Management. Flood Management Policy Series. Geneva: World Meteorological Organization.

WMO (2009). Integrated flood management: Concept paper. Geneva: World Meteorological Organization. 